\title{
Risk Stratification of Patients with AECOPD
}

\author{
Brian H. Rowe
}

Published online: 14 September 2013

(C) Springer Science+Business Media New York 2013

\begin{abstract}
Acute exacerbations of chronic obstructive pulmonary disease (AECOPD) are a common cause of dyspnea presentations to the emergency department in many developed countries. Since admission to the hospital is common, severity assessment matched to treatment decisions are important considerations in the timely management of this condition. Currently, there is no universally accepted approach to severity assessment and risk stratification, and a multi-pronged approach is required. In general, a history and physical examination should be supplemented with chest radiographs, blood gas measurements and judicious use of common biomarkers (i.e., troponin, D-dimer and brain natriuretic peptide) to determine the severity of a presentation. The role of novel biomarkers (e.g., C-reactive protein and procalcitonin) are evolving, although clarity has not emerged. Finally, multi-attribute scales to predict AECOPD severity and adverse events are currently under development and may be in use in the near future.
\end{abstract}

Keywords AECOPD - Emergency department .

Exacerbations · Severity · Assessment

\section{Abbreviations \\ ABG Arterial blood gas \\ AECOPD Acute exacerbation of chronic obstructive pulmonary disease}

B. H. Rowe $(\square)$

Department of Emergency Medicine and School of Public Health, University of Alberta Hospital, University of Alberta, Room 1G1.43 WMC, 8440-112th Street, Edmonton, AB T6G 2B7, Canada

e-mail: brian.rowe@ualberta.ca

B. H. Rowe

Alberta Health Services (AHS), Edmonton, AB, Canada

$\begin{array}{ll}\text { BNP } & \text { Brain natriuretic peptide } \\ \text { CAP } & \text { Community acquired pneumonia } \\ \text { CI } & \text { Confidence interval } \\ \text { CDR } & \text { Clinical decision rule } \\ \text { COPD } & \text { Chronic obstructive pulmonary disease } \\ \text { CRP } & \text { C-reactive protein } \\ \text { CTAS } & \text { Canadian Triage and Acuity Scale } \\ \text { ED } & \text { Emergency Department } \\ \text { FEV } 1 & \text { Forced expired volume in } 1 \mathrm{~s} \\ \text { FVC } & \text { Forced vital capacity } \\ \text { GOLD } & \text { Global initiative for chronic obstructive lung } \\ & \text { disease } \\ \text { MRC } & \text { Medical Research Council } \\ \text { OR } & \text { Odds ratio } \\ \text { PEF } & \text { Peak expiratory flow } \\ \text { PCT } & \text { Procalcitonin } \\ \text { PE } & \text { Pulmonary embolism } \\ \text { VTE } & \text { Venous thromboembolism }\end{array}$

\section{Introduction}

Chronic obstructive pulmonary disease (COPD) is one of the few major chronic diseases in which mortality has been increasing over the past decade [1]. Global mortality due to COPD is forecast to more than double over 30 years [2], making it the third leading cause of death worldwide by 2020. Individuals with COPD are prone to exacerbations of their illness, which are characterized clinically by symptoms of worsening dyspnea, cough, sputum production and sputum purulence, as well as by worsening of airflow obstruction [3]. It is difficult to predict expected exacerbation rates for individual patients; however, most patients with COPD experience one to four exacerbations per year. 
As airflow obstruction becomes more severe, exacerbations occur more frequently. In the US in 2000, there were 8 million physician office or hospital outpatient visits for COPD, 1.5 million emergency department (ED) visits and 673,000 hospitalizations [4].

Patients who live with COPD are prone to developing worsening of their symptoms, which can lead to acute exacerbations. These exacerbations can be triggered by upper respiratory tract infections, medication non-compliance, air pollution and other factors. Expert panels define acute exacerbations of chronic obstructive pulmonary disease (AECOPD) as "a sustained worsening of dyspnea, cough or sputum production, for at least 2 days, leading to an increase in the maintenance medications and/or supplementation with additional medications" [5]. There are a number of consequences of AECOPD: increased symptoms and dyspnea, lung function deterioration (both acute and permanent) [6], decreased quality of life [7], increased health care utilization [8] and mortality (both short and long term) $[9,10]$. Thus, treatment and prevention of a COPD exacerbation are two of the most important goals in the outpatient management of this disease.

Patients with AECOPD commonly present to acute care settings such as an ED with increased symptoms; however, they may be unaware of their diagnosis [11]. In one clinical trial of corticosteroids in AECOPD, $\sim 10 \%$ of enrolled patients received their diagnosis in the ED setting [11]. While patients with AECOPD present with variable symptoms and severity, some patients may demonstrate quite advanced disease in the ED. For example, in a North American study, over $59 \%$ of patients presenting to the ED with COPD symptoms required hospitalization, ED length of stay was nearly $6 \mathrm{~h}$, and mechanical ventilation was higher than in other acute respiratory presentations such as asthma [12]. In a Canadian study, an adult $>55$ years of age with a COPD exacerbation presents to an Alberta ED every $37 \mathrm{~min}$, over $33 \%$ of COPD cases require admission, $5.7 \%$ relapse back to the ED within 1 week, and follow-up occurs a median of 13 days after discharge [13•].

In light of the severe nature and high mortality rates of acute COPD, it is not surprising that there are a number of guidelines that have been developed to direct the management of this problem [1, 5, 14-17]. Despite the availability of these guidelines, limited data exist on the assessment of severity. The following article reviews what is know about diagnosis and severity assessment in the acute setting and how recent literature has shaped the field. The article was based on relevant publications in the past 3 years [including searches using Medical Subject Heading (MeSH) terms such as COPD_diagnosis AND severity] in MEDLINE. The search was neither exhaustive nor com- prehensive, likely over-represents the English language published literature and makes no effort to account for publication bias.

\section{COPD Diagnosis in Acute Care}

One of the important factors in the assessment of AECOPD severity is making the initial diagnosis correctly [18-20•]. The acute literature is replete with information suggesting that the diagnosis of COPD is often delayed or misdiagnosed [21••]. In one ED-based study of patents over the age of 55 who presented with wheezing, many were diagnosed with asthma and had findings consistent with COPD [12].

While according to the global initiative for chronic obstructive lung disease (GOLD) criteria, a post-bronchodilator the ratio of forced expired volume in $1 \mathrm{~s}\left(\mathrm{FEV}_{1}\right)$ as well as forced vital capacity (FVC) $<0.7$ is currently the accepted diagnostic criterion for COPD, most acute care settings do not complete formal spirometry on patients with COPD. In fact, even peak expiratory flow (PEF) measurements are rarely performed in the ED setting; one Canadian study found only $46 \%$ of 501 consecutive patients had PEF recorded at presentation [22•]. Moreover, some patients with COPD diagnosis have a near-normal spirometry and $\mathrm{FEV}_{1} / \mathrm{FVC}$ ratio.

Without a pulmonary function measurement confirming COPD, a specialist diagnosis of COPD or a previous diagnosis of COPD, emphysema or chronic bronchitis in a smoker over the age of 55 presenting to an ED with wheezing has been shown to be valid and reliable for the diagnosis of COPD [21••]. It is important to understand that a diagnosis of "asthma" in a heavy smoker or a patient with previous smoking history is often incorrect; these patients typically have COPD. It is also worth noting that for diagnosis, comparison of the $\mathrm{FEV}_{1} / \mathrm{FVC}$ ratio to the lower limits of normal adjusted for age and height may be preferable [23] to a fixed ratio of 0.7 , as the fixed ratio can lead to a false-positive diagnosis in the elderly because of the age-associated drop in elastic recoil and corresponding drop in $\mathrm{FEV}_{1}$ relative to $\mathrm{FVC}$.

Other tests can assist in determining whether the patient has COPD. First, plain radiographs of the chest almost always demonstrate hyperinflation during an exacerbation, and the presence of bulla and other radiographic criteria on advanced [especially computed tomography (CT)] imaging can confirm a COPD diagnosis. Finally, clinicians should not forget the power of the patient's story. A diagnosis of chronic bronchitis in a patient with a $\mathrm{FEV}_{1} / \mathrm{FVC}$ ratio $>0.7$ is made entirely by review of the patient's symptom of productive cough for 3 or more months for 3 consecutive years $[24 \bullet \bullet]$. 


\section{Assessment of Severity}

No single measure of severity assessment is available for AECOPD, and measurement of multiple factors is often the best approach. In almost every guideline on COPD, including the GOLD guideline, traditional approaches are recommended as follows, starting with history and physical examination [25].

\section{History}

A brief history and physical examination pertinent to the AECOPD, should be conducted concurrently with the prompt initiation of therapy, especially with signs of severe respiratory distress. The history should include: time of onset and cause of the present exacerbation; a simple grade and duration of symptoms (documenting sputum volume, sputum purulence and dyspnea) [3], including changes in activity limitations and baseline function; all current medications (including the dose and device being employed, adherence to the prescribed regimen, "action plan" and response to any recent medication escalation); and risk factors for COPD-related hospitalization or death. Patients with previous histories of intubation, recent exacerbations and/or hospitalizations suggest severe disease and a cautious approach to disposition [25]. In a study of 501 AECOPD patients presenting to Canadian EDs, multivariable logistic regression modeling demonstrated that a history of $\geq 2$ admissions for COPD in the past 2 years was strongly associated with hospitalization $(\mathrm{OR}=2.1,95 \%$ CI 1.2-3.6) [22•]. In the same study, ever having received oral corticosteroids for COPD was another factor associated with admission $(\mathrm{OR}=1.7,95 \% \mathrm{CI}$ $1.1-2.7)$.

\section{Vital Signs}

At presentations to the ED, most patients with AECOPD have abnormal vital signs; however, patients with more severe disease present with higher respiratory rates and lower oxygen saturations [22•]. Obviously temperature (to detect hyper- or hypo-thermia), pulse rate and respiratory rate are critical in assessing severity. Oxygen saturation should be closely monitored, preferably by pulse oximetry. This is especially useful in severe disease because objective measurements of lung function may be difficult because of dyspnea and fatigue. Lower oxygen saturation is reported in patients requiring hospitalization [22•]; however, the absolute level predicting the need for hospitalization is less clear. Once again, collection of formal vital signs is universally expected in EDs and would be reasonably simple to apply to patient care decisions.
Triage Score

Many EDs employ a triage ("sorting") score at presentation to the ED. In a study of 501 AECOPD patients presenting to Canadian EDs all employing the Canadian Triage and Acuity Scale (CTAS), in multivariable logistic regression modeling CTAS 1 or 2 (indicating severe disease) was associated with a twofold increase in hospital admission $(\mathrm{OR}=2.0,95 \%$ CI 1.3-3.1) [22•]. Although the tool for triage varies across jurisdictions, these assessments are relatively commonly collected in most EDs and would be reasonably simple to apply to patient-oriented care decisions.

\section{Physical Examination}

Once the vital signs and triage have been completed, a focused physical examination should be conducted. In stable patients, evidence regarding the test characteristics of physical signs has been summarized [26]; however, the evidence in the acute setting is lacking. The physical examination should assess exacerbation severity by evaluating the patient's ability to speak, posture, presence of subcutaneous emphysema, tracheal deviation and "tug," use of accessory muscles and other parenchymal sounds [i.e., air entry, wheezing/crackles, inspiratory:expiratory (I:E) ratio]. The examination should attempt to identify any potentially complicating factors (e.g., pneumonia, atelectasis, pneumothorax or pneumomediastinum).

\section{Pulmonary Measurements}

Airway measurements such as PEF or $\mathrm{FEV}_{1}$ are strongly recommended in AECOPD as physical examination alone may not fully indicate the severity of the exacerbation. Without delaying treatment, a baseline airway measurement (e.g., PEF or FEV ${ }_{1}$ ) should be obtained prior to the initiation of treatment and should be a component of the initial triage. Subsequent measurements can be made at appropriate intervals to determine whether there is any measurable response to treatment.

Severity of airflow obstruction can then be classified as mild $\left(\mathrm{FEV}_{1} \geq 80 \%\right.$ predicted), moderate $\left(50 \% \leq \mathrm{FEV}_{1}\right.$ $<80 \%$ predicted), severe $\left(30 \% \leq \mathrm{FEV}_{1}<50 \%\right.$ predicted) and very severe $\left(\mathrm{FEV}_{1}<30 \%\right.$ predicted). While spirometry is used to diagnose obstructive lung disease, stratification based on airway obstruction in the acute setting does not provide a good predictor of mortality in COPD.

\section{Response to Treatment}

Severity can also be assessed based on the response to therapy in the ED. While most patients with severe disease 
receive short-acting bronchodilators, systemic corticosteroids and some require antibiotics, all admitted patients receive more aggressive treatment. For example, in AECOPD patients presenting to Canadian EDs, those who received adjunct COPD treatments in the ED had higher risk of hospitalization $(\mathrm{OR}=3.9,95 \%$ CI 2.5-6.4) [22•].

\section{Diagnostic Imaging Investigations}

\section{Radiography}

A chest radiograph is usually required in AECOPD, especially if the presentation is associated with a suspected comorbid cardiopulmonary process, in those obviously requiring hospitalization and in those not responding to treatment where a pulmonary complication may be difficult to diagnose clinically. The concomitant diagnosis of community-acquired pneumonia (CAP) or pneumothorax may be an important causative finding for patients with AECOPD.

In patients with AECOPD complicated by CAP, the use of pneumonia scoring tools has been explored, including the pneumonia severity index [27], CURB (confusion, urea, respiratory rate, blood pressure) [28] and CURB-65 (CURB and age $\geq 65$ ) [29]. In one study of 920 AECOPD patients with a $10 \%$ in-hospital mortality, the five strongest predictors of mortality [extended Medical Research Council (MRC) Dyspnea Score, eosinopenia, consolidation, acidemia and atrial fibrillation] were combined to form the DECAF score, which outperformed the CURB-65 CAP severity tool [30•*]. Given the similarities of the various CAP severity tools, it is perhaps more important to employ one in assessing severity than the actual scoring system selected [31].

\section{Advanced Radiography}

Computerized tomography (CT) images are rarely required in patients with AECOPD, unless a suspicion of pulmonary embolism (PE) or other suspected intra-thoracic complication is present. Obviously, concomitant AECOPD and $\mathrm{CAP}$ or PE is an indication of severity requiring admission to the hospital for further acute and preventive management. Given the costs and radiation risks associated with CT scans, their use should be selective. Most assessments of PE include a calculation of a pre-test probability using the Wells [32] or Geneva [33] scoring systems and a serum D-dimer test (see "Biomarkers" section below). Some evidence suggests that PEs occur more frequently in patients for whom a cause of the AECOPD cannot be found, and these patients also have a higher risk of death extending for over 1 year after ED presentation [34•].

\section{Laboratory Investigations}

Given the advanced patient age and concomitant comorbidities associated with COPD, laboratory testing is often ordered and required in AECOPD. Moreover, while not in common use, some suggest combinations of simple laboratory tests may predict in-patient mortality [35॰].

\section{Electrolytes and Complete Blood Work (CBC)}

Both serum electrolytes and CBC are frequently ordered in AECOPD. Chronic renal failure and hyponatremia have been associated with adverse events and should be carefully considered in admission decisions. Anemia is a component of the CAP score, and its presence in any patient with AECOPD should stimulate a search for the cause. Clearly, serious comorbidities such as anemia, hyponatremia and/or renal disease [35•] should indicate a more severe case of AECOPD.

\section{Arterial Blood Gas (ABG)}

Since the degree of hypoxemia is not always indicated by physical examination alone, arterial oxygen saturation measurements are strongly recommended as a measure of severity of the exacerbation in some guidelines. Although not required in all AECOPD cases, ABG measurements should be completed in patients with severe obstruction, those who do not respond to initial treatment or when there is concern regarding deterioration. In many cases, venous blood gas measurements provide sufficiently robust evidence upon which to judge acidosis and hypercarbia and can replace ABGs. The patient should continue on supplemental oxygen while the measurement is made if necessary. A $\mathrm{PaO}_{2}<60 \mathrm{mmHg}(8 \mathrm{kPa})$ and a normal or increased $\mathrm{PaCO}_{2}$ (especially $>45 \mathrm{mmHg}, 6 \mathrm{kPa}$ ) indicate the presence of respiratory failure and may warrant airway interventions as well as hospitalization.

$\mathrm{PCO}_{2}$ was a significant predictor of admission in one Canadian observational study $(\mathrm{OR}=4.7,95 \%$ CI 1.8-12.4); however, due to the large number of missing observations, it could not be included in the final regression model [22•]. In a recent retrospective study from New Zealand, hypoxemic $\left(\mathrm{PaO}_{2}<60 \mathrm{mmHg}\right)$ patients $(\mathrm{OR}=2.0,95 \% \mathrm{CI} 1.03-3.80)$ and hyperoxemic $\left(\mathrm{PaO}_{2}\right.$ $>100 \mathrm{mmHg}$ ) patients $(\mathrm{OR}=2.37,95 \%$ CI $1.34-4.20)$ both experienced more serious adverse outcomes compared to normooxemic patients [36]. In clinical practice, it's unlikely that all patients will have venous or ABG samples ordered, so it may be better to follow other markers unless considering patients for non-invasive ventilation. In addition, evidence is mounting that oxygen therapy should be titrated to a target oxygen saturation of 88-92\% [36]. 


\section{Biomarkers}

Many patients with AECOPD present with a history of other common chronic conditions such as coronary artery disease (i.e., angina, myocardial infarction, bypass surgery and/or angioplasty/stents), diabetes mellitus, hypertension, peripheral vascular disease, cerebrovascular disease (i.e., transient ischemic attacks, hemorrhages and stroke) and chronic renal disease. Since these comorbidities can be exacerbated in patients with AECOPD or contribute to an exacerbation, it is important to search for their presence where valid biomarkers exist.

The role of biomarkers in the assessment of severity of AECOPD is an emerging field; however, the evidence is rapidly changing, and the role of these measures in emergency medicine remains unclear. Moreover, a variety of potential measurements have been studied and are briefly discussed below.

\section{Troponin}

Cardiovascular comorbidities are common in patients with COPD. Exacerbations may be the result of cardiovascular disease, including acute cardiac ischemia. In a study of 244 patients with AECOPD hospitalized over 1 year without evidence of concomitant cardiac comorbidities, an elevated troponin level was detected in nearly $17 \%$ of patients and was strongly associated with 30-day mortality $(\mathrm{OR}=6.3$, $95 \%$ CI 2.4-6.5) [37•]. In another study, elevations in a more sensitive troponin marker were frequent and strongly associated with 30-day mortality (OR $=4.5,95 \% \mathrm{CI}$ 1.2-16) even for small troponin elevations, especially in the setting of tachycardia [38]. Others have identified similar observations [39].

Parenthetically, novel research has suggested that the mechanism behind the increased cardiovascular risk associated with AECOPD may be the result of increased platelet aggregation during the acute phase [40]. While these observations await confirmation and larger studies, the theory is a compelling one that could lead to improved treatments.

\section{Brain Natriuretic Peptide (BNP)}

Brain natriuretic peptide (or its precursor NT-proBNP) is a biomarker commonly employed in heart failure. Given the advanced age of patients who present to the ED with AECOPD, and the common association of AECOPD with right heart failure and other cardiovascular comorbidities, BNP measurement may be helpful. In a study of 244 patients with AECOPD hospitalized over 1 year without evidence of concomitant cardiac comorbidities, elevated
NT-proBNP was common $(27.5 \%)$ and was strongly associated with 30 -day mortality [37•].

In a systematic review of all studies involving BNP or NT-proBNP in undifferentiated patients with dyspnea [41•], the evidence appears less compelling. Using evidence from five studies involving $>2,500$ patients, the authors concluded that BNP testing did not decrease hospital admission ( $\mathrm{OR}=0.82$, $95 \%$ CI 0.67-1.01); however, it did reduce length of stay $(-1.22$ days, $95 \% \mathrm{CI}$ -2.3 to -0.14$)$. Overall, mortality did not improve significantly. Given the limited number of trials and their heterogeneity, it remains difficult to draw firm conclusions from this literature.

\section{D-dimer}

D-dimer is a breakdown product of thrombi and is used to help diagnose venous thromboembolism (VTE). In patients with ill-defined dyspnea seen in the ED setting, it is often used in conjunction with a clinical decision rule (CDR) to rule in or rule out a PE. Common CDRs used in this setting include the Wells [32] or Geneva [33] score. In a large meta-analysis of 52 studies involving 55,268 patients, the role of the CDRs in conjunction with D-dimer was explored. The authors concluded that any CDR (including "gestalt") will help to rule out PE in conjunction with D-dimer testing [42•].

\section{C-reactive protein $(\mathrm{CRP})$}

C-reactive protein is a marker of general inflammation and has been shown to be elevated in patients with stable COPD. In a study of hospitalized patients, an elevated CRP (>48 mg/l) was shown to have high sensitivity (91\%, $95 \%$ CI 80-97) and specificity (93\%, $95 \%$ CI 86-98) for identifying patients with pneumonia [18]. Its use as a biomarker specific for AECOPD is unclear.

\section{Procalcitonin}

Procalcitonin (PCT) is a peptide precursor of the hormone calcitonin and has been used to diagnose infections such as pneumonia and sepsis. Its use is uncommon in most ED settings; however, some indirect evidence is available. In a European trial, patients with symptoms of lower respiratory tract infection (LRTI) were randomized to receive antibiotics based on a PCT algorithm (e.g., predefined cutoff ranges for initiating or stopping antibiotics) compared to standard guidelines. The trial demonstrated the safety of this strategy and lower rates of antibiotic exposure and antibiotic-associated adverse effects [19].

A 2012 Cochrane systematic review on the topic confirms these early European observations [20•]. The review 
involved 14 trials and 4,221 participants, and suggested that the PCT-directed antibiotic use for acute LRTI provided similar outcomes; however, the use was lower, as was the duration of antibiotic use (difference $=-3.47$, $95 \%$ CI -3.78 to -3.17 ). While PCT levels could be used to guide antibiotic therapy and may reduce antibiotic overuse in hospitalized patients with acute respiratory illness, their added value above and beyond other diagnostic markers in AECOPD at this stage is unclear.

In summary, biomarkers and personalized medical care, are rapidly expanding areas of research and activity. It seems appropriate to use troponin, BNP and perhaps D-dimer testing judiciously to rule out comorbid conditions that may have important influence on the outcomes of the exacerbation. CRP and PCT await further research.

\section{Severity Assessment Tools}

Chronic obstructive pulmonary disease severity can also be assessed using a variety of different scoring or severity tools; however, most are related to predicting in-hospital and 30-day mortality [43]. At present there is no consensus as to which severity stratification system should be used when evaluating acute and/or long-term prognosis [5].

Acute exacerbations of chronic obstructive pulmonary disease have been classified clinically using the Anthonisen criteria for many years, and this classification is important for treatment decisions [3]. These criteria require clinicians to evaluate the following symptoms: increased sputum volume, increased sputum purulence and dyspnea. The presence of three symptoms designates patients with type I, two symptoms as type II and one symptom as type III. Since most patients with AECOPD have at least dyspnea, when carefully questioned, the majority are classified as type I or II.

The BODE index, which is a composite index that takes into account body mass index, airway obstruction, dyspnea and exercise capacity, has recently been shown to predict survival better than $\mathrm{FEV}_{1}$ alone [44]. This index is likely impractical within the ED as airway obstruction would be accentuated during AECOPD and evaluating exercise capacity with a 6-min walk within the ER is likely impractical.

The MRC dyspnea scale is a relatively simple 5-point scale that stratifies patients based on their level of breathlessness using five statements (see Table 1) [45, 46]. Previous work has shown that the MRC scale predicts mortality better than $\mathrm{FEV}_{1}$ in COPD [46]. While dyspnea would be elevated during AECOPD, evidence exists that suggests when hospitalized patients were asked to categorize their MRC dyspnea prior to their AECOPD presentation, the MRC severity was still able to predict 3-year mortality [47]. In addition, patients with a higher MRC
Table 1 MRC severity grading for COPD

\begin{tabular}{ll}
\hline $\begin{array}{l}\text { MRC } \\
\text { grades }\end{array}$ & $\begin{array}{l}\text { Sample question } \\
\text { Grade 1 }\end{array} \quad \begin{array}{c}\text { Are you ever troubled by breathlessness except on } \\
\text { strenuous exertion? }\end{array}$ \\
Grade 2 & $\begin{array}{c}\text { Are you short of breath when hurrying on the level or } \\
\text { walking up a slight hill? }\end{array}$ \\
Grade 3 & $\begin{array}{c}\text { Do you have to walk slower than most people on the } \\
\text { level? } \\
\text { Do you have to stop after a mile or so (or after one- } \\
\text { quarter hour) on the level at your own pace? }\end{array}$ \\
Grade 4 & $\begin{array}{c}\text { Do you have to stop for breath after walking about 100 } \\
\text { yards (or after a few minutes) on the level? }\end{array}$ \\
Grade 5 & $\begin{array}{c}\text { Are you too breathless to leave the house or breathless } \\
\text { after undressing? }\end{array}$ \\
\hline
\end{tabular}

dyspnea scale pre-AECOPD were found to have an increased length of hospital stay. Thus, at present, the MRC dyspnea scale appears to be a reasonable tool to stratify COPD in the ED.

Finally, the BAP-65 (elevated BUN, altered mental status, pulse $>109$ beats/min, age $>65$ years) tool has been developed and validated; however, its use is uncommon in clinical practice [21••]. In the validation study involving 34,699 admissions to 177 US hospitals in 2007, the BAP65 system captured severity of illness resource use. The authors concluded that BAP-65 is a simple and sensible tool to categorize patients with AECOPD as to their risk for adverse outcomes. Although of interest, this tool has limited application to the acute care setting, since it does not provide insight into who should be admitted and who might experience an unexpected adverse event.

Preliminary work has been completed on the development of a CDR for determining the risk of developing an adverse event associated with an ED presentation for AECOPD [48]. Unfortunately, the tool is not ready for universal application and remains relatively complex. While further validation is required, the advantage to this tool is its rigorous development methods (e.g., prospective, multicentered, large sample) and comprehensive outcomes; this tool should provide direction in the future.

In summary, until specific AECOPD tools are developed for use in the acute setting, using the Anthonisen criteria for antibiotic decisions, the MRC scale for prognosis and any of the pneumonia CDRs for assessing risk of death from pneumonia appear to be appropriate approaches.

\section{Provocative Tests}

Much like other conditions seen in the acute care setting, provocative testing may be helpful to assess severity in AECOPD. Informal bedside functional testing (e.g., the 
"road test") has been used anecdotally in acute care settings for years while formalized 6-min walk tests have been used in stable COPD patients. The 3-min walk test has been explored in AECOPD and heart failure patients as a predictor of future adverse events. In multivariable modeling, it appears to be predictive of adverse events only for patents with heart failure [49]. While some form of provocative test within the ED may be clinically helpful for individual patients, there seems little evidence of its role in identifying patients who are at risk for adverse events in the immediate future.

\section{Summary and Conclusions}

Chronic obstructive pulmonary disease is a common and frequently debilitating disease. The assessment of severity in the acute setting is critically important to determining the pharmacologic and non-pharmacologic treatment approaches to control the exacerbation. Overall, many of the recommendations discussed in this article are based on consensus or small, low-quality studies that fail to provide strong evidence to support recommendations. Moreover, the recent evidence on novel biomarkers, while informative, is sparse or weak, and further research is urgently required. Consequently, there is no universally accepted approach to severity assessment and risk stratification in AECOPD, and a multi-pronged approach is required.

\section{Compliance with Ethics Guidelines}

Conflict of Interest Brian H. Rowe is supported as a Tier I Canada Research Chair in Evidence-based Emergency Medicine by the Canadian Institutes for Health Research (CIHR) through the Government of Canada (Ottawa, Canada). Since 2010, Dr. Rowe has received support for participation in medical research from industry sponsors with an interest in COPD including ElectroCore, Inc., MedImmune/AstraZeneca, Cempra and GlaxoSmithKline. Dr. Rowe does not own stocks or other ownership interest in any of these companies and is neither a paid consultant nor employee of these companies.

Human and Animal Rights and Informed Consent This article does not contain any studies with human or animal subjects performed by any of the authors.

\section{References}

Papers of importance, published recently, have been highlighted as:

- Of importance

•. Of major importance

1. NHLBI Who Workshop Report. Global strategy for the diagnosis, management, and prevention of chronic obstructive pulmonary disease, 2006: 1-88.
2. Stoller JK. Clinical practice. Acute exacerbations of chronic obstructive pulmonary disease. N Engl J Med. 2002;346:988-94.

3. Anthonisen N, Manfreda J, Warren P, Hershfield E, Harding G, Nelson N. Antibiotic therapy in exacerbation of chronic obstructive pulmonary disease. Ann Intern Med. 1987;106:196-204.

4. Mannino DM, Homa DM, Akinbami LJ, Ford ES, Redd SC. Chronic obstructive pulmonary disease surveillance-United States, 1971-2000. CDC Surveillance Summaries, MMWR. 2002;51:1-16.

5. O'Donnell DE, Aaron S, Bourbeau J, et al. Canadian Thoracic Society recommendations for management of chronic obstructive pulmonary disease-2007 update. Can Respir J. 2007;14:5B-32B.

6. Donaldson GC, Seemungal TA, Bhowmik A, Wedzicha JA. Relationship between exacerbation frequency and lung function decline in chronic obstructive pulmonary disease. Thorax. 2002; 57:847-52.

7. Seemungal TA, Donaldson GC, Paul EA, Bestall JC, Jeffries DJ, Wedzicha JA. Effect of exacerbation on quality of life in patients with chronic obstructive pulmonary disease. Am J Respir Crit Care Med. 1998;157:1418-22.

8. FitzGerald JM, Haddon JM, Bradly-Kennedy C, Kuramoto L, Ford GT. Resource use study in COPD (RUSIC): a prospective study to quantify the effects of COPD exacerbations on health care resource use among COPD patients. Can Respir J. 2007;14:145-52.

9. Almagro P, Calbo E, Ochoa de Echaguen A, et al. Mortality after hospitalization for COPD. Chest. 2002;121:1441-8.

10. Groenewegen KH, Schols AM, Wouters EF. Mortality and mortality-related factors after hospitalization for acute exacerbation of COPD. Chest. 2003;124:459-67.

11. Aaron S, Vandemheen K, Hebert P, et al. Outpatient oral prednisone after emergency treatment of chronic obstructive pulmonary disease. N Engl J Med. 2003;348:2618-25.

12. Cydulka RK, Rowe BH, Clark S, Emerman CL, Camargo CA Jr. Emergency department management of acute exacerbations of chronic obstructive pulmonary disease in the elderly: the Multicenter Airway Research Collaboration. J Am Geriatr Soc. 2003; 51:908-16.

13. - Rowe BH, Voaklander DC, Marrie TJ, Senthilselvan A, Klassen TP, Rosychuk RJ. Outcomes following chronic obstructive pulmonary disease presentations to emergency departments in Alberta: a population-based study. Can Respir J. 2010;17:295300. Large administrative database study providing populationbased age- and sex-adjusted estimates of outcomes from AECOPD presentations in one Canadian province.

14. Roche N, Lepage T, Bourcereau J, Terrioux P. Guidelines versus clinical practice in the treatment of chronic obstructive pulmonary disease. Eur Respir J. 2001;18:903-8.

15. Laitinen LA, Koskela K. Chronic bronchitis and chronic obstructive pulmonary disease: Finnish National Guidelines for Prevention and Treatment 1998-2007. Respir Med. 1999;93:297-332.

16. The COPD Guidelines Group of the Standard of Care Committee of the BTS. BTS Guidelines for the Management of Chronic Obstructive Pulmonary Disease. Thorax. 1997;52:S1-S28.

17. American Thoracic Society. Standards for the diagnosis and care of patients with chronic obstructive pulmonary disease. Am J Respir Crit Care. 1995; 152:S77-120.

18. Bafadhel M, Clark TW, Reid C, et al. Procalcitonin and C-reactive protein in hospitalized adult patients with communityacquired pneumonia or exacerbation of asthma or COPD. Chest. 2011;139:1410-8.

19. Schuetz P, Christ-Crain M, Thomann R, et al. Effect of procalcitonin-based guidelines vs standard guidelines on antibiotic use in lower respiratory tract infections: the ProHOSP randomized controlled trial. JAMA. 2009;302:1059-66.

20. - Schuetz P, Muller B, Christ-Crain M, et al. Procalcitonin to initiate or discontinue antibiotics in acute respiratory tract 
infections. Cochrane Database Syst Rev. 2012;9:CD007498. This Cochrane review summarizes the best available evidence regarding the use of procalcitonin to decide on antibiotic discontinuation in respiratory tract infections.

21. • Shorr AF, Sun X, Johannes RS, Yaitanes A, Tabak YP. Validation of a novel risk score for severity of illness in acute exacerbations of COPD. Chest. 2011;140:1177-83. Large validation study of a risk stratification score for hospitalized patients with AECOPD in the US. BAP-65 (elevated BUN, altered mental status, pulse $>109$ beats/min, age $>65$ years).

22. • Rowe BH, Villa-Roel C, Guttman A, et al. Predictors of hospital admission for chronic pulmonary disease exacerbations in Canadian Emergency Departments. Acad Emerg Med. 2009;16:316-24. This study of patients with AECOPD in emergency departments in Canada provides a list of risk factors associated with hospital admission.

23. Hardie JA, Buist AS, Vollmer WM, Ellingsen I, Bakke PS, Morkve O. Risk of over-diagnosis of COPD in asymptomatic elderly never-smokers. Eur Respir J. 2002;20:1117-22.

24. • Chapter 2: Diagnosis and assessment. In: Global strategy for the diagnosis, management and prevention of COPD, global initiative for chronic obstructive lung disease (GOLD). 2013. p. 9-18 http://wwwgoldcopdorg/. The GOLD guideline was updated in 2012 and represents the most current international COPD guideline.

25. Chapter 5: Management of exacerbations. In: Global strategy for the diagnosis, management and prevention of COPD, global initiative for chronic obstructive lung disease (GOLD). 2013. p. 40-45. http://wwwgoldcopdorg/.

26. Holleman DR, Simel DL. Does the clinical examination predict airflow limitation? JAMA. 1995;273:313-9.

27. Fine MJ, Auble TE, Yealy DM, et al. A prediction rule to identify low risk patients with community-acquired pneumonia. N Engl J Med. 1997;336:243-50.

28. Neill AM, Martin IR, Weir R, et al. Community acquired pneumonia: aetiology and usefulness of severity criteria on admission. Thorax. 1996;51:1010-6.

29. Lim WS, van der Eerden MM, Laing R, et al. Defining community acquired pneumonia severity on presentation to hospital: an international derivation and validation study. Thorax. 2003;58:377-82.

30. • Steer J, Gibson J, Bourke SC. The DECAF Score: predicting hospital mortality in exacerbations of chronic obstructive pulmonary disease. Thorax. 2012;67:970-6. A study of AECOPD patients with pneumonia in which five factors (a dyspnea score, eosinopenia, consolidation, acidaemia and atrial fibrillation) were combined to form the DECAF score, which was associated with higher mortality.

31. Buising KL, Thursky KA, Black JF, et al. A prospective comparison of severity scores for identifying patients with severe community acquired pneumonia: reconsidering what is meant by severe pneumonia. Thorax. 2006;61:419-24.

32. Wells PS, Anderson DR, Rodger M, et al. Excluding pulmonary embolism at bedside without diagnostic imaging: management of patients with suspected pulmonary embolism presenting to the emergency department by using a simple clinical model and D-dimer. Ann Intern Med. 2001;135:98-107.

33. Wicki J, Perneger TV, Funod AF, et al. Assessing clinical probability of pulmonary embolism in the emergency ward. Arch Intern Med. 2001;161:92-7.

34. - Gunen H, Gulbas G, In E, Yetkin O, Hacievliyagil SS. Venous thromboemboli and exacerbations of COPD. Eur Respir J. 2010; 35:1243-8. An important study documenting that pulmonary embolisms occurred more frequently in patients for whom a cause of the AECOPD could not be found, and this finding was associated with a higher risk of death extending for over 1 year after ED presentation.
35. - Asiimwe AC, Brims FJ, Andrews NP, et al. Routine laboratory tests can predict in-hospital mortality in acute exacerbations of COPD. Lung. 2011; 189:225-32. A clinically useful risk prediction model for mortality that used laboratory data such as serum albumin, urea and arterial $\mathrm{pCO}_{2}$ from the first $24 \mathrm{~h}$ of admission in AECOPD.

36. Cameron L, Pilcher J, Weatherall M, Beasley R, Perrin K. The risk of serious adverse outcomes associated with hypoxaemia and hyperoxaemia in acute exacerbations of COPD. Postgrad Med J. 2012;88:684-9.

37. • Chang CL, Robinson SC, Mills GD, et al. Biochemical markers of cardiac dysfunction predict mortality in acute exacerbations of COPD. Thorax. 2011;66:764-8. A study of patients hospitalized with AECOPD over 1 year without evidence of concomitant cardiac comorbidities, which demonstrated that an elevated NTproBNP was common (27.5\%) and was strongly associated with 30-day mortality.

38. Hoiseth AD, Neukamm A, Karlsson BD, Omland T, Brekke PH, Soyseth V, et al. Elevated high-sensitivity cardiac troponin $\mathrm{T}$ is associated with increased mortality after acute exacerbation of chronic obstructive pulmonary disease. Thorax. 2011;66:775-81.

39. Soyseth V, Bhatnagar R, Holmedahl NH, et al. Acute exacerbation of COPD is associated with fourfold elevation of cardiac troponin T. Heart. 2013;99:122-6.

40. Maclay JD, McAllister DA, Johnston S, et al. Increased platelet activation in patients with stable and acute exacerbation of COPD. Thorax. 2011;66:769-74.

41. - Lam LL, Cameron PA, Schneider HG, Abramson MJ, Muller C, Krum H.et al. Meta-analysis: effect of B-type natriuretic peptide testing on clinical outcomes in patients with acute dyspnea in the emergency setting. Ann Intern Med. 2010;153:728-35. A systematic review examining the role of B-type natriuretic peptide in patients with dyspnea in the emergency setting. Using evidence from five studies involving more $>2,500$ patients, the authors conclude that BNP testing did not decrease hospital admission.

42. - Lucassen W, Geersing GJ, Erkens PM, et al. Clinical decision rules for excluding pulmonary embolism: a meta-analysis. Ann Intern Med. 2011;155:448-60. A systematic review and metaanalysis of the role of clinical decision rules in excluding pulmonary embolism. Overall, the review suggested that deciding to use a decision rule was perhaps more important than the exact tool selected.

43. Steer J, Gibson GJ, Bourke SC. Predicting outcomes following hospitalization for acute exacerbations of COPD. QJM. 2010;103:817-29.

44. Celli BR, Cote CG, Marin JM, et al. The body-mass index, airflow obstruction, dyspnea, and exercise capacity index in chronic obstructive pulmonary disease. N Engl J Med. 2004;350:1005-12.

45. Fletcher CM, Elmes PC, Fairbairn AS, Wood CH. The significance of respiratory symptoms and the diagnosis of chronic bronchitis in a working population. Br Med J. 1959;2:257-66.

46. Nishimura K, Izumi T, Tsukino M, Oga T. Dyspnea is a better predictor of 5-year survival than airway obstruction in patients with COPD. Chest. 2002;121:1434-40.

47. Tsimogianni AM, Papiris SA, Stathopoulos GT, Manali ED, Roussos C, Kotanidou A. Predictors of outcome after exacerbation of chronic obstructive pulmonary disease. J Gen Intern Med. 2009;24:1043-8.

48. Stiell IG, Clement CM, Rowe $\mathrm{BH}$, et al. A prediction rule for emergency department patients with chronic obstructive pulmonary disease. Acad Emerg Med. 2011;18:S230.

49. Stiell IG, Clement CM, Brison RJ, et al. A risk scoring system to identify emergency department patients with heart failure at high risk for serious adverse events. Acad Emerg Med. 2013;20:17-26. 